\title{
Perancangan Jaringan Backhaul Sistem Transmisi Gelombang Mikro Digital Menggunakan Frequency Diversity di Wilayah Kepulauan Riau
}

Yosy Rahmawati ${ }^{1}$, Ade Wahyudin ${ }^{2}$

${ }^{1}$ Progam Studi D3 Teknik Telekomunikasi, Institut Teknologi Telkom Purwokerto

${ }^{2}$ Progam Studi S1 Teknik Telekomunikasi, Institut Teknologi Telkom Purwokerto

\section{Informasi Makalah}

Dikirim, 20 Agustus 2018

Direvisi, 04 September 2018

Diterima, 05 September , 2018

\section{Kata Kunci: \\ ICT}

Backhaul

Gelombang Mikro

Frequency Diversity

Pathloss 5.0

\begin{abstract}
INTISARI
Kemajuan teknologi informasi dan komunikasi mengakibatkan sejumlah desa di Kabupaten Lingga, Kepulauan Riau masih merasakan minimnya informasi publik karena keterbatasan signal. Salah satu pulau yang menjadi sorotan pemerintah yaitu Pulau Pekajang. Secara ekonomi penduduk Pulau Pekajang lebih banyak berinteraksi dengan Pulau Bangka. Jarak yang cukup jauh dan fasilitas perhubungan yang sangat minim membuat Pulau Pekajang terisolir. Oleh karena itu, untuk menyediakan layanan ICT diperlukan jaringan backhaul untuk mendukung akses layanan ICT. Pada penelitian telah dilakukan perancangan jaringan backhaul sistem transmisi gelombang mikro menggunakan frequency diversity dan tanpa diversity di wilayah kepulauan riau. Dari hasil pengujian rancangan dengan menggunakan Simulator Pathloss 5.0, maka didapatkan nilai kehandalan sistem yang menggunakan frequency diversity yaitu $99.96879 \%$ dan tanpa diversity yaitu $99.81417 \%$. Dapat disimpulkan hasil perancangan sistem transmisi gelombang mikro menggunakan frequency diveristy layak untuk dapat diterapkan karena memiliki nilai kehandalan sistem diatas ambang batas berdasarkan standar ITU-R G.827 dan F.1703.
\end{abstract}

\begin{abstract}
The progress of information and communication technology has resulted in a number of villages in Lingga Regency, Riau Islands still feeling the lack of public information due to signal limitations. One of the islands in the spotlight of the government is Pekajang Island. Economically the population of Pekajang Island interacts more with Bangka Island. A considerable distance and very minimal transportation facilities make Pekajang Island isolated. Therefore, to provide ICT services, a backhaul network is needed to support access to ICT services. In the study, a backhaul network of microwave transmission systems has been designed using frequency and diversity without diversity in the Riau archipelago. From the results of the design test using Pathloss 5.0 Simulator, the reliability value of the system that uses frequency diversity is $99.96879 \%$ and without diversity is $99.81417 \%$. It can be concluded that the design results of a microwave transmission system using frequency diveristy are feasible to be applied because it has a system reliability value above the threshold based on ITU-R G.827 and F.1703 standards.
\end{abstract}

\section{Korespondensi Penulis:}

Yosy Rahmawati

Program Studi D3 Teknik Telekomunikasi

Institut Teknologi Telkom Purwokerto

JL. D.I Panjaitan No 128 Purwokerto Kidul, Purwokerto Selatan, Banyumas 53147

Email: yosy@ittelkom-pwt.ac.id

\section{PENDAHULUAN}

Kemajuan teknologi informasi dan komunikasi mengakibatkan sejumlah desa di Kabupaten Lingga, Kepulauan Riau masih merasakan minimnya informasi publik karena keterbatasan signal. Kabupaten Lingga memiliki luas wilayah 2.266,77 km², jumlah penduduk 94.962 orang, 10 Kecamatan, 7 Kelurahan dan 75 Desa [1]. Salah satu kecamatan yang menjadi sorotan pemerintah yaitu Kecamatan Pekajang, Desa Pekajang. Desa Pekajang merupakan desa terluar Kabupaten Lingga. Batas wilayah Desa Pekajang meliputi sebelah 
Utara Tanjung Nyang, Desa Teluk Indragiri Hilir, sebelah timur Selat Karimata, sebelah selatan Provinsi Kepulauan Bangka Belitung dan sebelah barat Provinsi Jambi [2]. Desa Pekajang terdiri dari tujuh buah pulau, diantaranya Pulau Pekajang Kecil/Cebia, Pulau Pekajang Besar, Pulau Penyaman, Pulau Pasir Keliling, Pulau Tokong Kembung, Pulau Tokong Kembung dan Pulau Lalang [1]. Dari tujuh pulau tersebut hanya satu buah pulau yang dihuni yaitu Pulau Pekajang Kecil (Cebia) dengan luas keseluruhan kurang lebih $1756 \mathrm{~km}^{2}$. Secara ekonomi penduduk Pulau Pekajang lebih banyak berinteraksi dengan penduduk Pulau Bangka, Kecamatan Belinyu, Kabupaten Bangka. Jaraknya lebih 30 mil laut atau 55,56 km, bila dibandingkan dari Kecamatan Lingga Kabupaten Lingga Provinsi Kepulauan Riau yang berjarak kurang lebih 60 mil laut atau 111,12 km ke Desa Pekajang [2].

Berdasarkan informasi yang termuat pada website yang dikelola secara resmi pemerintah Kabupaten Lingga pada tanggal 25 Januari, menyatakan bahwa guna pemerataan akses telekomunikasi di Kabupaten Lingga, Dinas Kominfo Lingga sudah berkoordinasi dengan pihak Telkomsel dalam hal penambahan atau peningkatan layanan telekomunikasi untuk beberapa daerah di Kabupaten Lingga [2]. Adapun daerah yang baru mendapatkan tambahan pembangunan tower telekomunkasi pada tahun 2017 diantaranya Desa Batu Berdaun, Bukit Cening, Desa Penuba, Desa Kerandin, Desa Tanjung Bungsu dan Desa Rantau Panjang. Sedangkan untuk peningkatan layanan dari 3G menjadi 4G pada tahun 2018 yakni Pelabuhan Tanjung Buton, Pelabuhan Jagoh dan Senayang. Diketahui sebelumnya sudah 4 daerah di seputaran Kota Dabo dan dan 3 site di seputaran Kota Daik yang sudah mendapatkan layanan 4G LTE [2]. Dengan adanya penambahan dan peningkatan kualitas layanan ini, tentunya bisa membantu dan mempermudah masyarakat Kabupaten Lingga dalam mengakses jaringan telekomunikasi. Harapan kedepan, daerah yang belum terjangkau jaringan telekomunikasi dapat diakomodir pada tahun 2018 ini, seperti Desa Tanjung Kelit atau Pelabuhan Sei Tenam, Desa Mentude, Desa Batu Belubang, Desa Kudung, Belungkur dan Desa Teluk. Sedangkan untuk Desa Pekajang diakomodir melalui program Universal Service Obligation (USO) dari kementrian Kominfo yang rencananya akan terealisasi pada tahun 2018 [2].

Untuk 2018, Telkomsel akan terus melakukan pembangunan untuk perluasan area dan peningkatan layanan di area Kabupaten Lingga. Hal ini dilakukan sejalan dengan komitmen Telkomsel yang akan terus membangun dan melayani negeri sebagai operator "Merah Putih” yang paling Indonesia [2]. Untuk perluasan jaringan, Telkomsel membutuhkan support dari pemerintah daerah dan masyarakat setempat terkait ketersediaan lahan dan listrik sebagai catuan utama. Kemudahan akses transmisi juga menjadi faktor utama disamping ketersediaan listrik [2]. Oleh karena itu, untuk mengatasi permasalahan diatas terutama untuk membantu terlaksananya program Universal Service Obligation (USO), maka pada penelitian ini akan dilakukan Perancangan Sistem Transmisi Gelombang Mikro Digital Menggunakan Teknik Space Diversity dan Tanpa Diversity di Wilayah Riau Kepulauan agar harapan masyarakat yang menginginkan kendala komunikasi di Pulau Pekajang dapat terselesaikan secepatnya dan untuk meminimalisir solusi yang diupayakan pemerintah baik daerah maupun provinsi mengalami berkali-kali gagal.

Berdasarkan pada penelitian sebelumnya yang dilakukan oleh Zein Hanni Perdana yang berjudul Analisis Optimasi Space Diversity Pada Link Microwave Menggunakan ITU Models yang dipublikasikan pada jurnal JETT pada tahun 2018 menyimpulkan bahwa terjadi peningkatan availabiity yang signifikan dari 99,96949\% menjadi 99,98767\% dengan menggunakan metode space diversity [3]. Sehingga pada penelitian ini menggunakan metode yang berbeda yaitu frequency diversity. Oleh karena itu pada penelitian ini, penulis mengangkat judul penelitian yaitu perancangan jaringan backhaul sistem transmisi gelombang mikro menggunakan frequency diversity dan tanpa diversity di wilayah kepulauan riau. Tujuan dari penelitian ini adalah untuk merancang, mensimulasikan dan menguji perfomansi sistem berdasarkan nilai availability yang berstandarkan kepada ITU-R G.827 dan F.1703 dengan menggunakan metode frequency diversity.

\section{METODOLOGI PENELITIAN}

\subsection{Diagram Alir Penelitian}

Dalam perancangan jaringan backhaul sistem transmisi gelombang mikro menggunakan frequency diversity dan tanpa diversity, akan menggunakan frekuensi kerja $2000 \mathrm{MHz}$ dengan polarisasi vertikal. Data inisialisasi dapat dilihat pada Tabel 1 dibawah ini :

Tabel 1 Data Inisialisasi Perancangan Jaringan Backhaul Sistem Transmisi Gelombang Mikro

\begin{tabular}{|c|c|c|}
\hline Parameter & Pulau Pekajang & Pulau Bangka \\
\hline Frequency (MHz) & 200 & \\
\hline Polarization & Ver & \\
\hline
\end{tabular}

Proses perancangan akan diawali dengan penentuan lokasi site bertujuan untuk melihat jalur yang akan digunakan dalam perancangan agar sesuai dengan kondisi real di lapangan. Kemudian perancangan point to point, perancangan frequency diversity dan tanpa diversity, pengujian rancangan dengan menggunakan simulator pathloss 5.0 dan analisa kehandalan sistem transmisi gelombang mikro berdasarkan standar ITU-R G.827 dan F.1703[4]. Diagram Alir penelitian dapat dilihat pada Gambar 1 dibawah ini :

Techno Vol. 19, No. 2, Oktober 2018: $63-70$ 


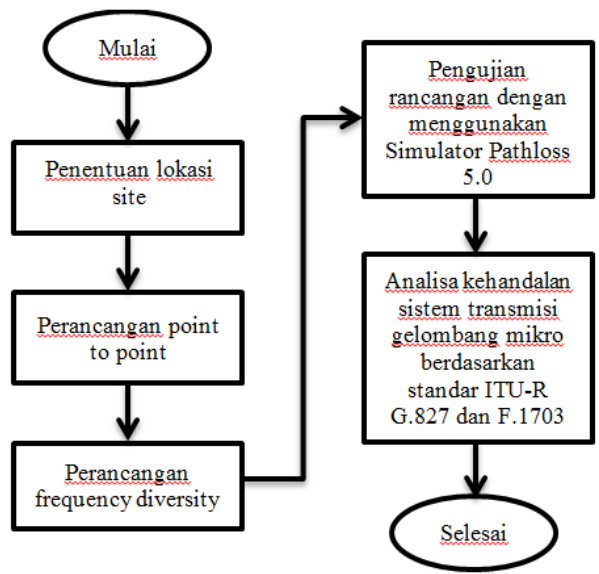

\subsection{Penentuan Lokasi Site}

Gambar 1 Diagram Alir Penelitian

Peta rute dibuat untuk melihat jalur yang akan digunakan dalam perancangan jaringan backhaul sistem transmisi gelombang mikro dan juga melihat kondisi geografisnya secara umum. Lokasi yang akan dijadikan stasiun berjumlah 2 site dengan koordinatnya terlampir pada Tabel 2 dibawah ini :

Tabel 2 Lokasi Site

\begin{tabular}{lcc}
\hline \multicolumn{1}{c}{ Parameter } & Pulau Pekajang & Pulau Bangka \\
\hline Latitude & $011240.00 \mathrm{~S}$ & $013735.50 \mathrm{~S}$ \\
Longitude & $1051603.00 \mathrm{E}$ & $1054410.50 \mathrm{E}$ \\
Elevation $(\mathrm{m})$ & 40.00 & 2.50 \\
Path length $(\mathrm{km})$ & \multicolumn{2}{c}{69.51} \\
\hline
\end{tabular}

Dengan menggunakan path profile berdasarkan peta map info, dapat diketahui kondisi wilayah tempat pengalihan jaringan backhaul sistem transmisi gelombang mikro yang akan direncanakan, yaitu site Pulau Pekajang dan Site Pulau Bangka dengan jarak antar site 69,51 km. Untuk path profle dapat dilihat pada Gambar 2 dibawah ini :

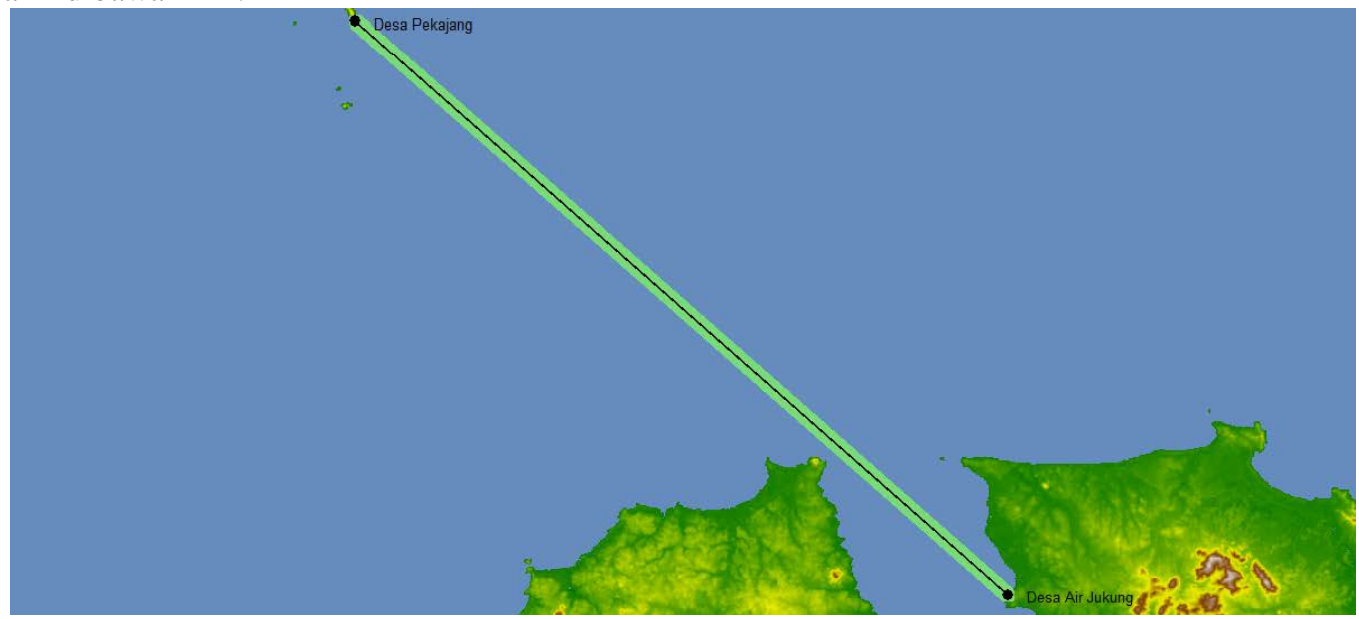

Gambar 2 Path Profile

\subsection{Perancangan Point to Point Microwave}

\section{a. Gain Antenna TR-TR}

Gain Antenna adalah parameter utama dalam perancangan point to point microwave. Gain ditunjukkan dalam bentuk decibel ( $\mathrm{dBi}$ ) yang merupakan kemampuan antena mengarahkan radiasi sinyal atau penerimaan sinyal dari arah tertentu[4][5]. Besarnya nilai gain dipengaruhi oleh frekuensi kerja, diameter antena dan efisiensi antena. Secara teoritis, Gain Antenna (GTX) ditunjukan oleh persamaan dibawah ini[3][5] :

Keterangan :

$$
G_{T x}=20 \log f+20 \log d+10 \log \eta+20.4
$$

$\mathrm{G}_{\mathrm{Tx}}=$ gain/penguatan antena $(\mathrm{dBi})$

$\eta=$ efisiensi antena $(\%)$

$\mathrm{d}=$ diameter antena $(\mathrm{m})$

$\mathrm{f}=$ frekuensi kerja yang digunakan $(\mathrm{GHz})$

Hasil hitung nilai Gain Antenna dapat dilihat pada Tabel 3 dibawah ini : 
Tabel 3 Data Inisialisasi Gain Antenna TR-TR

\begin{tabular}{lcc}
\hline \multicolumn{1}{c}{ Parameter } & Pulau Pekajang & Pulau Bangka \\
\hline Antenna model & HPX15-19F & HPX15-19F \\
Antenna file name & 1441 & 1441 \\
Antenna gain (dBi) & 37.40 & 37.40 \\
Antenna height (m) & 94.81 & 107.60 \\
\hline
\end{tabular}

\section{b. Effectif Isotropic Radiated Power (EIRP)}

EIRP merupakan besaran yang menyatakan kekuatan daya pancar suatu antena. EIRP diperoleh dengan menjumlahkan daya output dari antena pemancar dengan gain antenna lalu dikurangkan oleh loss. Secara teoritis, EIRP dapat dihitung dengan rumus sebagai berikut [6][5] :

$$
\mathrm{EIRP}=\mathrm{P}_{\mathrm{Tx}}+\mathrm{G}_{\mathrm{Tx}}-\mathrm{L}_{\mathrm{Tx}}
$$

(2)

Keterangan :

$\mathrm{EIRP}=$ effective isotropic radiated power $(\mathrm{dBm})$

$\mathrm{P}_{\mathrm{Tx}}=$ daya pancar $(\mathrm{dBm})$

$\mathrm{G}_{\mathrm{Tx}}=$ gain/penguatan antena $(\mathrm{dBi})$

$\mathrm{L}_{\mathrm{Tx}}=$ rugi-rugi pada pemancar $(\mathrm{dB})$

Untuk menghitung nilai EIRP maka diperlukan data inisialisasi seperti yang terlampir pada Tabel 4 dibawah ini :

Tabel 4 Data Inisialisasi EIRP

\begin{tabular}{lcc}
\hline \multicolumn{1}{c}{ Parameter } & Pulau Pekajang & Pulau Bangka \\
\hline Antenna gain $(\mathrm{dBi})$ & 37.40 & 37.40 \\
TX line model & EWP17 & EWP17 \\
TX line unit loss $(\mathrm{dB} / 100 \mathrm{~m})$ & 1.19 & 1.19 \\
TX line length $(\mathrm{m})$ & 104.00 & 114.00 \\
TX line loss $(\mathrm{dB})$ & 1.24 & 1.36 \\
Connector loss $(\mathrm{dB})$ & 0.15 & 0.15 \\
Circulator branching loss $(\mathrm{dB})$ & 3.00 & 3.00 \\
TX power $(\mathrm{dBm})$ & 29.00 & 29.00 \\
\hline
\end{tabular}

\section{c. Isotropic Received Level (IRL)}

Isotropic Receive Level (IRL) adalah RF power level pada antena penerima. Dapat juga dikatakan sebagai power yang diukur sebuah isotropic antenna penerima. Secara teoritis, IRL dapat dihitung dengan rumus sebagai berikut [3], [7]:

Keterangan :

$$
\mathrm{IRL}=\mathrm{EIRP}-\mathrm{FSL}
$$

$\mathrm{IRL}=$ isotropic received level $(\mathrm{dBm})$

EIRP $=$ effective isotropic radiated power $(\mathrm{dBm})$

$\mathrm{FSL}=$ free space loss $(\mathrm{dB})$

Untuk menghitung nilai Isotropic Received Level maka diperlukan data inisialisasi seperti yang terlampir pada Tabel 5 dibawah ini :

Tabel 5 Data Inisialisasi Isotropic Received Level

\begin{tabular}{lcc}
\hline \multicolumn{1}{c}{ Parameter } & Pulau Pekajang & Pulau Bangka \\
\hline Free space loss $(\mathrm{dB})$ & \multicolumn{3}{c}{135.33} \\
Atmospheric absorption loss $(\mathrm{dB})$ & \multicolumn{3}{c}{0.42} \\
Net path loss $(\mathrm{dB})$ & 69.84 & 69.84 \\
EIRP $(\mathrm{dBm})$ & 62.01 & 61.89 \\
\hline
\end{tabular}

\section{d. Received Signal Level (RSL)}

Receive Signal Level (RSL) merupakan daya level daya yang diterima oleh perangkat pada sisi penerima. Nilai RSL dipengaruhi oleh redaman sepanjang link antara penerima dan pengirim serta dipengaruhi oleh gain dari sisi penerima. Level sinyal yang diterima di antena penerima dan nilainya harus lebih besar dari sensitivitas perangkat penerima (RSL $\geq$ Rth). Sensitivitas perangkat penerima merupakan kepekaan suatu perangkat pada sisi penerima yang dijadikan ukuran threshold. Nilai RSL dapat dihitung dengan persamaan berikut [6],[5] :

Keterangan :

$$
\mathrm{RSL}=\mathrm{IRL}+\mathrm{G}_{\mathrm{Rx}}-\mathrm{L}_{\mathrm{Tx}}
$$


$\mathrm{RSL}=$ received signal level $(\mathrm{dBm})$

$\mathrm{IRL}=$ isotropic received level $(\mathrm{dBm})$

$\mathrm{G}_{\mathrm{Rx}}=$ gain/penguatan antena $(\mathrm{dB})$

$\mathrm{L}_{\mathrm{Rx}}=$ receiver loss $(\mathrm{dB})$

Hasil hitung nilai Received Signal Level dapat dilihat pada Tabel 6 dibawah ini :

Tabel 6 Nilai Received Signal Level

\begin{tabular}{lcc}
\hline \multicolumn{1}{c}{ Parameter } & Pulau Pekajang & Pulau Bangka \\
\hline Rx threshold criteria & 1E-6 BER & 1E-6 BER \\
Rx threshold level $(\mathrm{dBm})$ & -69.50 & -69.50 \\
Receive signal $(\mathrm{dBm})$ & -40.84 & -40.84 \\
\hline
\end{tabular}

\section{e. Fade Margin (FM)}

Pada perambatan gelombang radio akan terjadi pemantulan oleh permukaan bumi, sehingga pada penerima akan menerima dua gelomabng yang berbeda yaitu gelombang langsung dan gelombang pantul yang jarak tempuh dan waktu perambatan yang berbeda sehingga menimbulkan level daya yang diterima berbeda pada ujung penerima. Perbedaan level daya terima untuk daya pancar yang tetap inilah disebut Fade Margin (FM). Nilai FM dapat dihitung dengan rumus sebagai berikut [3]:

Keterangan :

$$
\left.F M=30 \log D+10 \log (a x b x 2,5 x f)-10 \log U n A v_{\text {Path }}\right)-60
$$

$\mathrm{FM}=$ fading margin $(\mathrm{dB})$

$\mathrm{D}=$ panjang lintasan $(\mathrm{km})$

$\mathrm{f}$ : frekuensi kerja $(\mathrm{GHz})$

a : faktor kekasaran bumi

a : 4 ; untuk daerah halus, laut, danau, dan gurun

a : 1 ; untuk daerah kekasaran rata-rata, dataran

a : $1 / 4 ;$ untuk pegunungan dan dataran tinggi

b : faktor iklim

b : $1 / 2$; untuk daerah panas dan lembab

b : $1 / 4$; untuk daerah normal

b : $1 / 8$; untuk daerah pegunungan (sangat kering)

\section{f. Availability}

Availability merupakan ukuran kehandalan sistem. Secara ideal semua sistem harus memiliki availability 100\%. Namun hal tersebut tidak mungkin terpenuhi karena dalam suatu sistem pasti terdapat ketidakhandalan sistem (unavailability). Terdapat dua metode untuk memperhitungkan link budget terutama untuk avalability pada sistem yaitu metode Vigants-Barent dan metode rekomendasi ITU-R P.530-7/8. Metode Vigants-Barnet merupakan persamaan perhitungan yang digunakan untuk menghitung nilai availability sistem dari persamaan fading margin dengan memasukkan faktor jarak lintasan dan frekuensi kerja. Secara teoritis, rumus untuk menghitung availability seperti dibawah ini [8]:

Keterangan :

$$
A v_{\text {Path }}=\left(1-U n A v_{\text {Path }}\right) \times 100 \%
$$

$U n A v_{\text {Path }}=$ ketidakhandalan sistem

$A v_{\text {Path }}=$ kehandalan sistem

Sedangkan unavailability dapat dinyatakan dengan persamaan dibawah ini :

$$
U n A v_{\text {Path }}=\operatorname{axb} \times 2,5 \times f \times D^{3} \times 10^{-6} \times 10^{-F M / 10}
$$

\subsection{Perancangan Frequency Diversity}

Frequency diversity merupakan sistem yang mengoperasikan dua frekuensi gelombang mikro pada satu antena baik itu di pemancar maupun penerima. Informasi yang dikirimkan secara simultan dikirimkan kedua transmitter yang beroperasi pada frekuensi yang berbeda kemudian diteruskan ke satu antena pemancar. Pada antena penerima akan dikumpulkan informasi dan memisahkannya menjadi dua sinyal. Cara kerja dari frequency diversity dapat dilihat pada Gambar 3 dibawah ini [3]:

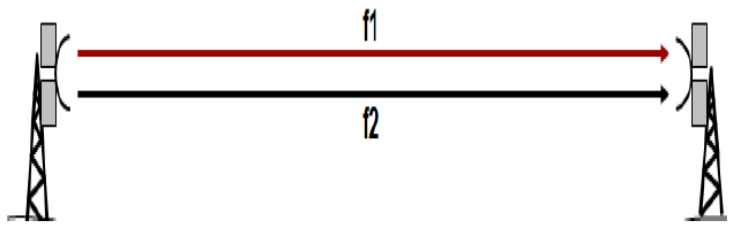

Gambar 3 Frequency Diversity 
Pada perancangan frequency diversity menggunakan dua frekuensi kerja yang terpisah masingmasing $29 \mathrm{MHz}$. Dua frekuensi kerja tersebut dapat dilihat pada Tabel 7 dibawah ini :

Tabel 7 Dua Frekuensi Kerja Frequency Diversity

\begin{tabular}{ccc} 
Parameter & $\begin{array}{c}\text { Pulau Pekajang } \\
\text { (MHz) }\end{array}$ & $\begin{array}{c}\text { Pulau Bangka } \\
\text { (MHz) }\end{array}$ \\
21 & 1753 & 1966 \\
11 & 1724 & 1937 \\
\hline
\end{tabular}

Dengan frequency diversity, maka akan didapatkan persamaan untuk mendapatkan fading margin dengan faktor perbaikan dari frequency diversity seperti dibawah ini [6]:

$$
I_{f d}=\frac{0.8 x \Delta f}{f^{2} x D} \times 10^{\frac{F M}{10}}
$$

Dimana, $\Delta f$ adalah perbedaan frequency diversity. Jika persamaan diatas diubah ke dalam desibel maka akan didapatkan persamaan sebagai berikut [6]:

$$
I_{f d}=10 \log \Delta f-20 \log f-10 \log D+F M 0.9
$$

Setelah sistem mendapatkan perbaikan, maka didapatkan persamaan fading margin dengan frequency diversity sebagai berikut [6]:

$$
F M=20 \log D+5 \log (a x b x 2.5)+15 \log f-5 \log U n A v_{\text {path }}-5 \log \Delta f-29.5
$$

Dimana,

$\Delta f=$ perbedaan frekuensi yang digunakan dalam sistem transmisi yang menggunakan teknik frequency diveristy

$I_{f d}=$ faktor perbaikan $(\mathrm{dB})$

Untuk menghitung nilai availability pada sistem gelombang mikro menggunakan frequency diversity dapat dilihat pada persamaan (6) (7).

\section{HASIL DAN PEMBAHASAN}

\subsection{Path Profile}

Dengan analisa path profile berdasarkan peta map info, dapat diketahui kondisi wilayah tempat perencanaan jaringan backhaul sistem transmisi gelombang mikro yang akan direncanakan yaitu site Pulau Pekajang dihubungkan ke site Pulau Bangka. Berdasarkan data dilapangan maka dapat dianalisis sebagai berikut :

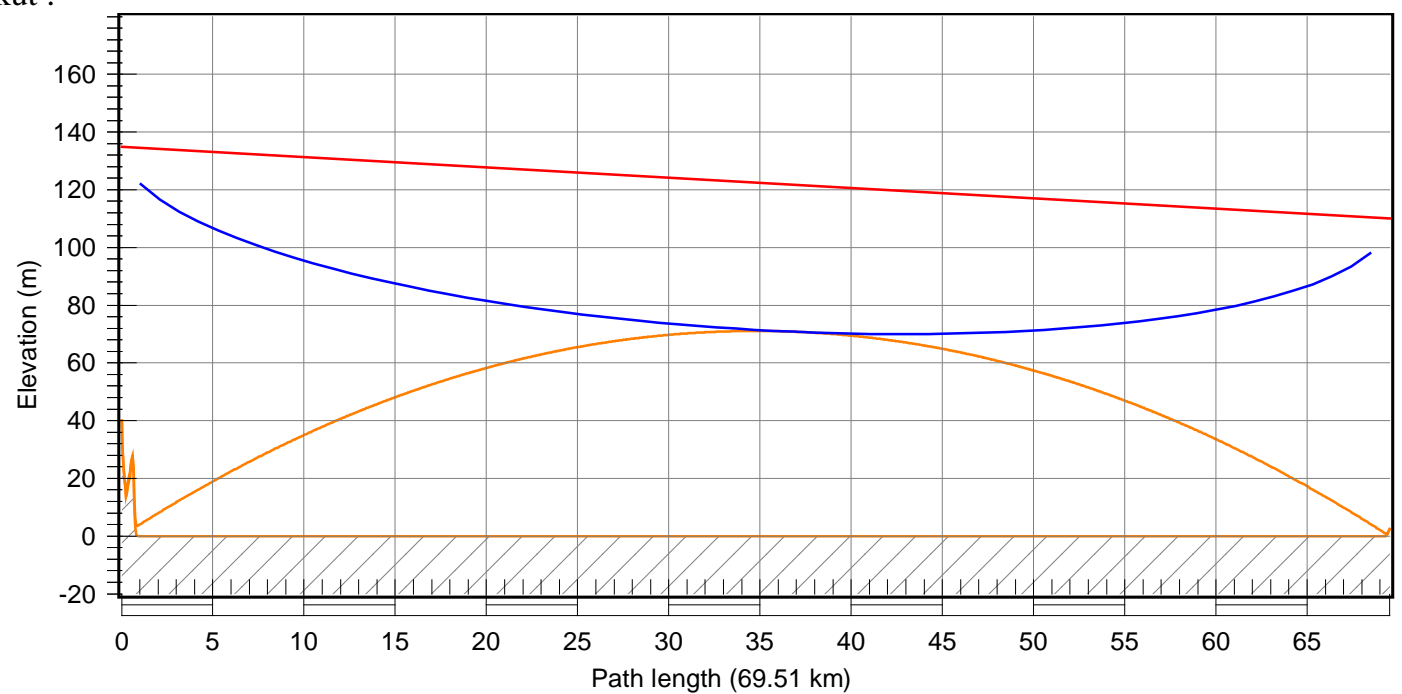

Gambar 4 Path Profile Site Pulau Pekajang menuju Site Pulau Bangka

Berdasarkan Gambar 4 diatas dapat dilihat path profile site Pulau Pekajang dan site Pulau Bangka dengan jarak $69.51 \mathrm{~km}$. Dimana terrain antar site tersebut adalah lautan dengan tinggi antena di Pulau Pekajang adalah 94.81 meter dan 107.60 meter di Pulau Bangka. Dengan mempertimbangkan faktor kelengkungan bumi (K factor) adalah 1.33, menghasilkan nilai fresnel zone 1 (F1) adalah 70.8 meter.

\subsection{Summary Report Tanpa Diverisity}

Berdasarkan hasil simulasi dengan menggunakan simulator pathloss 5.0 didapatkan hasil availability tahunan sebesar 99.81417\%. Nilai tersebut menghasilkan outage time sebesar 58603.03 detik/tahun. Nilai tersebut tidak memenuhi standar kualitas availability yang ditentukan oleh ITU-R G.827 
dan F.1703. Dimana, untuk komunikasi jaringan backhaul pada kriteria short haul harus memiliki nilai availability sebesar 99.9800 - 99.9966\%. Hasil summary report tanpa diversity dapat dilihat pada Tabel 8 dibawah ini :

Tabel 8 Summary Report Tanpa Diversity

\begin{tabular}{ccc}
\hline Parameter & Pulau Pekajang & Pulau Bangka \\
\hline Thermal fade margin (dB) & 28.66 & 28.66 \\
Effective fade margin (dB) & 28.53 & 28.53 \\
Annual 2 way multipath availability (\%) & \multicolumn{2}{c}{99.81417} \\
Annual 2 way multipath unavailability (sec) & \multicolumn{2}{c}{58603.03} \\
Annual rain availability (\%) & \multicolumn{2}{c}{100.00000} \\
Annual rain + multipath availability (\%) & 99.81417 \\
\hline
\end{tabular}

\subsection{Summary Report Menggunakan Frequency Diversity}

Dari hasil pengujian perancangan jaringan backhaul sistem transmisi gelombang mikro menggunakan frequency diveristy didapatkan nilai availability sebesar 99.96879\%. Nilai outage time sebesar 9843.76 detik/tahun. Nilai tersebut sudah memenuhi standar yang berlaku pada ITU-R G.827 dan F.1703 yaitu sebesar 99.9800 - 99.9966\%. Hasil summary report menggunakan frequency diversity dapat dilihat pada Tabel 9 dibawah ini :

Tabel 9 Summary Report Menggunakan Frequency Diversity

\begin{tabular}{ccc}
\hline Parameter & Pulau Pekajang & Pulau Bangka \\
\hline Thermal fade margin (dB) & 28.66 & 28.66 \\
Effective fade margin (dB) & 28.53 & 28.53 \\
Annual 2 way multipath availability (\%) & \multicolumn{2}{c}{99.96879} \\
Annual 2 way multipath unavailability (sec) & \multicolumn{2}{c}{9843.76} \\
Annual rain availability (\%) & \multicolumn{2}{c}{100.00000} \\
Annual rain + multipath availability (\%) & 99.96879 \\
\hline
\end{tabular}

Dapat disimpulkan bahwa dengan penggunaan frequency diversity dapat meningkatkan nilai availability sistem komunikasi gelombang mikro dengan nilai improvement factor sebesar 5.95.

\section{KESIMPULAN}

Dari hasil pengujian rancangan dengan menggunakan Simulator Pathloss 5.0, maka didapatkan kesimpulan antara lain :

1. Nilai kehandalan sistem yang menggunakan frequency diversity yaitu $99.96879 \%$ dan tanpa diversity yaitu $99.81417 \%$.

2. Nilai outage time menggunakan frequency diversity yaitu 8603.03 detik/tahun. Hal tersebut menunjukan sistem lebih baik daripada sistem tanpa diversity yang memiliki nilai

3. Dapat disimpulkan hasil perancangan sistem transmisi gelombang mikro menggunakan frequency diveristy layak untuk dapat diterapkan karena memiliki nilai kehandalan sistem diatas ambang batas berdasarkan standar ITU-R G.827 dan F.1703.

\section{UCAPAN TERIMAKASIH}

Penulis mengucapakan Terima Kasih kepada segenap akademisi Fakultas Teknik Telekomunikasi dan Elektro di Institut Teknologi Telkom Purwokerto atas bantuan secara moral sehingga penulis dapat menyelesaikan karya ilmiah ini dengan baik dan benar.

\section{DAFTAR PUSTAKA}

[1]. Lingga BK. Kabupaten Lingga Dalam Angka 2017 [Internet]. Kabupaten Lingga; 2017. Available from: https://linggakab.bps.go.id/publication/2017/08/12/97b6ecaf379aae252591cced/kabupaten-lingga-dalam-angka2017.html

[2]. Kabupaten Lingga. Kabupaten Lingga Bertingkap Alam Berpintu Illahi [Internet]. 2017 [cited 2018 Sep 5]. Available from: http://www.linggakab.go.id/

[3]. Pradana ZH, Wahyudin A. Analisis Optimasi Space Diversity Pada Link Microwave Menggunakan ITU Models. JTT. 2017;4(2):586-92.

[4]. Hikmaturrokhman A, Wahyudi E, Sulaiman H. Analisa Pengaruh Interferensi Terhadap Availability pada Jaringan Transmisi Microwave Menggunakan Software. Ecotipe. 2014;1(2):1-17.

[5]. Hikmaturokhman A, Wahyudin A, Alia S, Transmission AM. Comparison Analysis Of Passive Repeater Links Prediction Using Methods : Barnett Vigants \& ITU Models. In: CONMEDIA. Jakarta: Universitas Multimedia Nusantara; 2017. p. 142-7.

[6]. Dewanti IE, Wahyudin A, Hikmaturrokhman A. Analisis Perbandingan Passive Repeater Back-To-Back Antenna Dan Passive Repeater Plane Reflector Menggunakan Pathloss 5 . 0 Comparative Analysis of Passive 
Repeater Back-To-Back Passive Repeater Antenna and Plane Reflector Using the. In: SENATEK 2017. Purwokerto: Univeristas Muhammadiyah Purwokerto; 2017. p. 1-8.

[7]. $\quad$ Freeman RL. Telecommunication System Engineering. Fourth Edi. New Jersey: John Wiley \& Sons; 2004. 187$211 \mathrm{p}$.

[8]. Hikmaturokhman A, Wahyudin A. Analisa Perencanaan Kapasitas Jaringan Transport Operator X Untuk Mendukung Proyek Roll Out Area Jombang Rawa. In: SEMNAHUMTEK 2017. Purwokerto: STMIK Yos Sudarso Purwokerto; 2017. p. 1-10. 